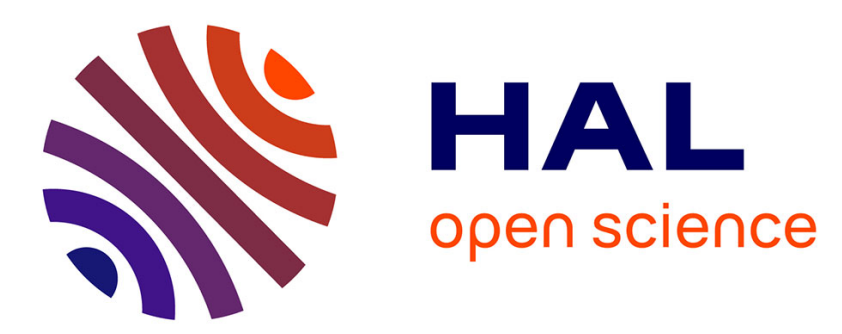

\title{
A Serenitatis origin for the Imbrian grooves and South Pole-Aitken thorium anomaly
}

Mark Wieczorek, Maria T. Zuber

\section{To cite this version:}

Mark Wieczorek, Maria T. Zuber. A Serenitatis origin for the Imbrian grooves and South PoleAitken thorium anomaly. Journal of Geophysical Research. Planets, 2001, 106 (E11), pp.27853-27864. 10.1029/2000JE001384. hal-02458520

\section{HAL Id: hal-02458520 \\ https://hal.science/hal-02458520}

Submitted on 26 Jun 2020

HAL is a multi-disciplinary open access archive for the deposit and dissemination of scientific research documents, whether they are published or not. The documents may come from teaching and research institutions in France or abroad, or from public or private research centers.
L'archive ouverte pluridisciplinaire HAL, est destinée au dépôt et à la diffusion de documents scientifiques de niveau recherche, publiés ou non, émanant des établissements d'enseignement et de recherche français ou étrangers, des laboratoires publics ou privés. 


\title{
A Serenitatis origin for the Imbrian grooves and South Pole-Aitken thorium anomaly
}

\author{
Mark A. Wieczorek and Maria T. Zuber \\ Department of Earth, Atmospheric and Planetary Sciences, Massachusetts Institute of Technology, Cambridge, \\ Massachusetts
}

\begin{abstract}
The northwest corner of the Moon's South Pole-Aitken (SPA) basin contains a high abundance of thorium and a unique Imbrian aged geomorphologic unit that consists of "grooves and mounds" (referred to here as the Imbrian grooves). Because the location of these features are almost antipodal to the Imbrium basin, where high-thorium ejecta and seismic energy are expected to have converged, an Imbrium origin for these units has long seemed certain. By modeling the deposition of impact ejecta on the Moon, we have investigated whether the convergence of Imbrium's ejecta at its antipode could be the origin of both the Imbrian grooves and SPA thorium anomaly. As a result of the Moon's rotation, our results show that ejecta from this basin should converge more than $12^{\circ}$ west of its antipode. Both the Imbrian grooves and thorium anomaly within SPA, however, reside slightly to the east of Imbrium's antipode. In an attempt to reconcile this disparity, the effects of a putative oblique Imbrium impact have been qualitatively investigated. While this model can distribute ejecta in the general vicinity of the Imbrian grooves, the planform of our modeled antipodal ejecta is distinctly different from that which is observed. As an alternative explanation for the origin of these features, we find that the modeled distribution of ejecta from an oblique Serenitatis impact is surprisingly similar to the planform of the Imbrian grooves, with the exception that it is offset directly to the east. This eastward offset is likely to be an artifact of our not being able to properly include the effects of the Moon's rotation in our oblique impact models. We conclude that the Imbrium grooves and SPA thorium anomaly are most consistent with having an origin from the convergence of ejecta antipodal to the Serenitatis basin. If this conclusion can be substantiated once quantitative ejecta scaling relations for oblique impacts are determined, then this implies that (1) the Serenitatis target contained a high abundance of thorium and (2) the convergence of seismic energy at the antipodes of either the Imbrium or Serenitatis basin was not sufficient to cause substantial surface modification. Extrapolating this result to Mercury suggests that the "hilly and lineated" terrain antipodal to the Caloris basin was formed by the convergence of ejecta, and not seismic waves.
\end{abstract}

\section{Introduction}

The Moon and Mercury both possess distinctive features, such as magnetic anomalies, swirl-like albedo markings, and degraded landforms, that correlate with the antipodes of major impact basins. While the origin for each of these is probably different, their ultimate cause is believed to reside in the spherical surface geometry of planetary bodies. For instance, many of the lunar magnetic anomalies are thought to have formed when an expanding impact-generated plasma cloud converged at a basin's antipode, amplifying ambient magnetic fields in the process [Hood and Huang, 1991; Hood and Williams, 1989]. The "hilly and lineated" terrain on Mercury [Trask and Dzurisin, 1984] and the "material of grooves and mounds" on the Moon [e.g., StuartAlexander, 1978] similarly are thought to have formed by either the convergence of basin ejecta [Moore et al., 1974] or seismic waves [Schultz and Gault, 1975] at the antipodes of the Caloris and Imbrium impact basins, respectively.

The evidence in favor of an Imbrium origin for the "material of grooves and mounds" on the Moon (hereafter referred to as the

Copyright 2001 by the American Geophysical Union.

Paper number 2000JE001384

0148-0227/01/2000JE001384\$09.00
Imbrian grooves) is particularly compelling. This unique highly modified region of the Moon is situated almost antipodal to the Imbrium basin, and its entire expanse appears to have formed nearly simultaneously within the Imbrian period [e.g., StuartAlexander, 1978]. Furthermore, models of the deposition of impact ejecta on a spherical body all predict a substantial quantity of ejecta to be found at Imbrium's antipode [e.g., Moore et al., 1974; Haskin, 1998]. Since the crust of the Imbrium target is widely believed to be enriched in thorium and other incompatible elements [e.g., Haskin, 1998; Haskin et al, 2000; Jolliff et al., 2000; Korotev, 2000; Wieczorek and Phillips, 2000], Haskin et al. [1996] and Haskin [1998] predicted that the Imbrium antipode should show a thorium enhancement as well. Gamma-ray data from the Lunar Prospector spacecraft have since confirmed this prediction [Lawrence et al., 1998, 1999], and L. A. Haskin et al. (personal communication, 2000) have further noted that the distribution of thorium within the South Pole-Aitken (SPA) basin is spatially correlated with the Imbrian grooves. Thus, while the convergence of seismic energy at Imbrium's antipode might have played a role in the formation of the Imbrian grooves, the convergence of basin ejecta at the Imbrium antipode is at least required to explain the thorium anomaly that is found in this region.

While we had no reason to initially doubt an Imbrium origin for the SPA thorium anomaly and Imbrian grooves, we were 
struck by the fact that these features are slightly offset and elongated from Imbrium's true antipode to both the east and north (see section 2 and Plates 1 and 2). As a result of the Moon's prograde rotation, however, it might have been expected that Imbrium's ejecta would have converged on a point slightly west of its antipode. In this paper we have investigated the deposition of basin ejecta on a spherical, rotating body using modern impact scaling relations in an attempt to model the formation of the Imbrian grooves and SPA thorium anomaly. Because the time of flight of ejecta on ballistic trajectories from one side of the Moon to the other is considerable (from hours to months), we show that Imbrium's ejecta should have converged at least $12^{\circ}$ west of its antipode if this basin was formed by a near-vertical impact. Including the Moon's rotation in calculating the distribution of Imbrium's antipodal ejecta thus exacerbates the discrepancy between the expected location of Imbrium's antipodal ejecta and the observed thorium anomaly within the South Pole-Aitken basin.

In an attempt to rectify this problem, we have considered how oblique impact conditions could have modified the distribution of ejecta antipodal to the Imbrium basin. Ejecta scaling relations for oblique impacts have not yet been formulated, and we parameterize this process in a simple way. As a result of our parameterization, however, our results should be considered only qualitatively accurate for the case in which the Moon does not rotate. These models indicate that if the Imbrium impact was in fact oblique, its antipodal ejecta would have been elongated in the direction of the impacting bolide. However, the planform of our modeled distribution of antipodal ejecta is found to be distinctly different from that of the Imbrian grooves. Our results for both vertical and oblique impact conditions thus seem to argue against an origin of the SPA thorium anomaly and Imbrian grooves by the convergence of ejecta antipodal to the Imbrium basin.

We argue that the most likely alternative explanation for these features is that they have an origin related to the Serenitatis impact. The Serenitatis basin is located about $35^{\circ}$ east of the Imbrium basin, and this impact crater shows clear geophysical evidence for having formed as a result of an oblique impact from either the north or south. If the direction of the Serenitatis bollide was from the north, then we find that our modeled planform of its antipodal ejecta is remarkably similar to that of the Imbrian grooves, with the exception that it is offset directly to the east. Since we cannot properly include the rotation of the Moon in our qualitative oblique model, this eastward offset was to be expected. Unfortunately, we cannot test at this point whether the magnitude of this offset is consistent with the Imbrian grooves having a Serenitatis origin or not. Nonetheless, a Serenitatis origin for the Imbrian grooves and SPA thorium anomaly appears at present to be the most likely explanation for these features.

In section 2 of this paper we first review the evidence that the Imbrian grooves and SPA thorium anomaly are spatially correlated and have a common origin. In section 3 we describe our model for computing the thickness of basin ejecta on a rotating spherical body. Our model results for the Imbrium and Serenitatis impacts are presented in section 4 , and we discuss the implications of these results in section 5 .

\section{Imbrian Grooves and SPA Thorium Anomaly}

We begin with a discussion of the features that we are attempting to explain: the South Pole-Aitken thorium anomaly and Imbrian grooves. Plate 1 shows the abundance of thorium within the South Pole-Aitken basin as determined from the Lunar Prospector gamma-ray spectrometer data [Lawrence et al., 1998, 1999]. This map illustrates that there is a high abundance of thorium $(\sim 5 \mathrm{ppm})$ within the northwest portion of this basin and that this anomaly is further divided into two distinct groups. Whereas the southernmost thorium anomaly is offset by only $\sim 5^{\circ}$ to the east of Imbrium's antipode, the other anomaly is offset by $\sim 10^{\circ}$ to both the east and north. As we remarked in section 1 , we might have expected the ejecta from the Imbrium impact to have converged at a point west of its antipode as a result of the Moon's rotation. In anticipation of our conclusions, we note that the entire thorium anomaly in this region is offset to the west of Serenitatis's antipode.

Plate 2 shows a simplified geologic map of the northern portion of the South Pole-Aitken basin taken from the mapping of Stuart-Alexander [1978]. Also shown is the $2^{\circ} \times 2^{\circ}$ thorium data of Lawrence et al. [1999] for the same region. This image shows that the two high-thorium anomalies seen in Plate 1 are spatially correlated with two young Eratosthenian craters. The northernmost of these craters appears to have formed within the Imbrian grooves unit, whereas the other crater appears to have formed just to the southeast of this unit. It is notable that none of the other craters (both Eratosthenian and Copernican) in this region possess thorium enhancements. While there is a moderate and diffuse enhancement of thorium east of the two Eratosthenian craters and west of Serenitatis's antipode, this enhancement does not appear to be correlated with any mapped geologic unit. Most of the mare basalt deposits in this area possess regionally low concentrations of thorium. To a good approximation, the Imbrian grooves unit is seen to possess a southwest-northeast symmetry axis with the planform of this unit being widest at the northeastern end.

While L. A. Haskin et al. (personal communication, 2000) were the first to note the close spatial correlation between the Imbrian grooves and SPA thorium anomaly using the thorium data of Lawrence et al. [1998], the data in Plate 2 show that this correlation is not exact. The fact that the largest thorium anomalies in this basin are associated with young Eratosthenian craters suggests that these craters excavated thorium-rich material from depth and deposited it at the surface. The most likely explanation for this observation is that this region of the Moon originally possessed a near-surface thorium enhancement that was subsequently buried by impact ejecta from the surrounding highlands (the Lunar Prospector gamma-ray spectrometer senses only the upper meter of the Moon's surface). Only later did young craters reexpose some of this buried material in isolated spots.

Since one of the high-thorium anomalies is located within the Imbrian grooves unit, and the other lies just outside of it, the material that makes up the Imbrian grooves is the most probable source of the thorium enhancement within this region of the South Pole-Aitken basin. However, we currently do not have a good explanation as to why the lowermost thorium anomaly appears to reside just outside of the Imbrian grooves unit, nor why the region to the east of this unit has a slight diffuse enhancement of thorium. Since the original thorium enhancement in this region of the Moon appears to have been covered up by local highland materials, while the surface expression of the Imbrian grooves has not, in the following ejecta modeling we will attempt only to explain the distribution of the Imbrian grooves. We acknowledge that there is a possibility that the Imbrian grooves and thorium anomaly could be genetically unrelated. If this turns out to be the case, then our ejecta 

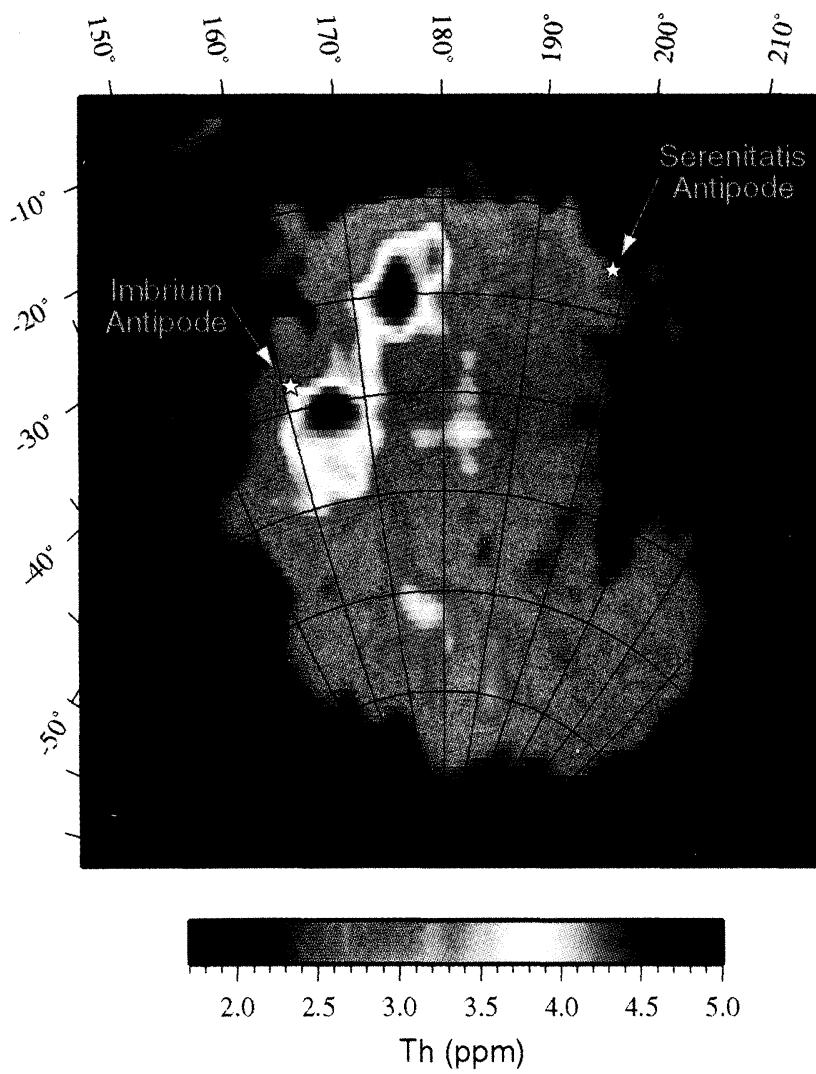

Plate 1. Plot of the abundance of thorium within the South PoleAitken (SPA) basin. Thorium concentrations are taken from the $2^{\circ} \times 2^{\circ}$ data of Lawrence et al. [1999] and have been extrapolated to a minimum curvature surface. We have corrected for an error in how gamma-ray counts were converted to abundances by Lawrence et al. [1999] by multiplying their data by a correction factor of 1.325 [see Lawrence et al., 2000]. The map is presented in an Albers equal-area projection, and the locations of the Imbrium and Serenitatis antipodes are shown for reference.

modeling below should be considered only as an explanation for the origin of the grooved terrain within the South Pole-Aitken basin.

We end this section by noting that distinctive geologic units have been mapped antipodal to other basins as well. For instance, magnetic anomalies and related high-albedo swirl-like markings are found antipodal to the Imbrium, Serenitatis, Orientale, and Crisium basins. The most plausible explanation for the magnetic anomalies is that they formed when an impact-generated plasma cloud expanded around the Moon and compressed the ambient magnetic field at the antipodes of these basins [Hood and Williams, 1989; Hood and Huang, 1991]. Furthermore, a geomorphologic unit referred to as "furrowed and pitted terrain" has been mapped antipodal to the Orientale basin [e.g., Wilhelms and El-Baz, 1997]. It is not clear, though, as to whether or not this unit has an origin similar to the Imbrian grooves. Without any discussion, Hood and Williams [1989] considered these two geomorphologic units to be synonymous. Stuart-Alexander [1978] however, noted that "no other lunar terrain is exactly like" the Imbrium grooves unit. Finally, a few isolated occurrences of "grooves" have been found near the antipode of the Serenitatis basin [e.g., Hood and Williams, 1989; Wilhelms, 1987]. However, as Wilhelms [1987] noted, these may simply be secondary craters related to the nearby Korolev, Hertzsprung, and Apollo basins.

\section{Ejecta Modeling}

Our method for computing the thickness of an impact basin's ejecta at its antipode is relatively simple. First, we determine the volume and velocity of material ejected from each point on the preimpact surface of the impact basin. Then, for a given ejection
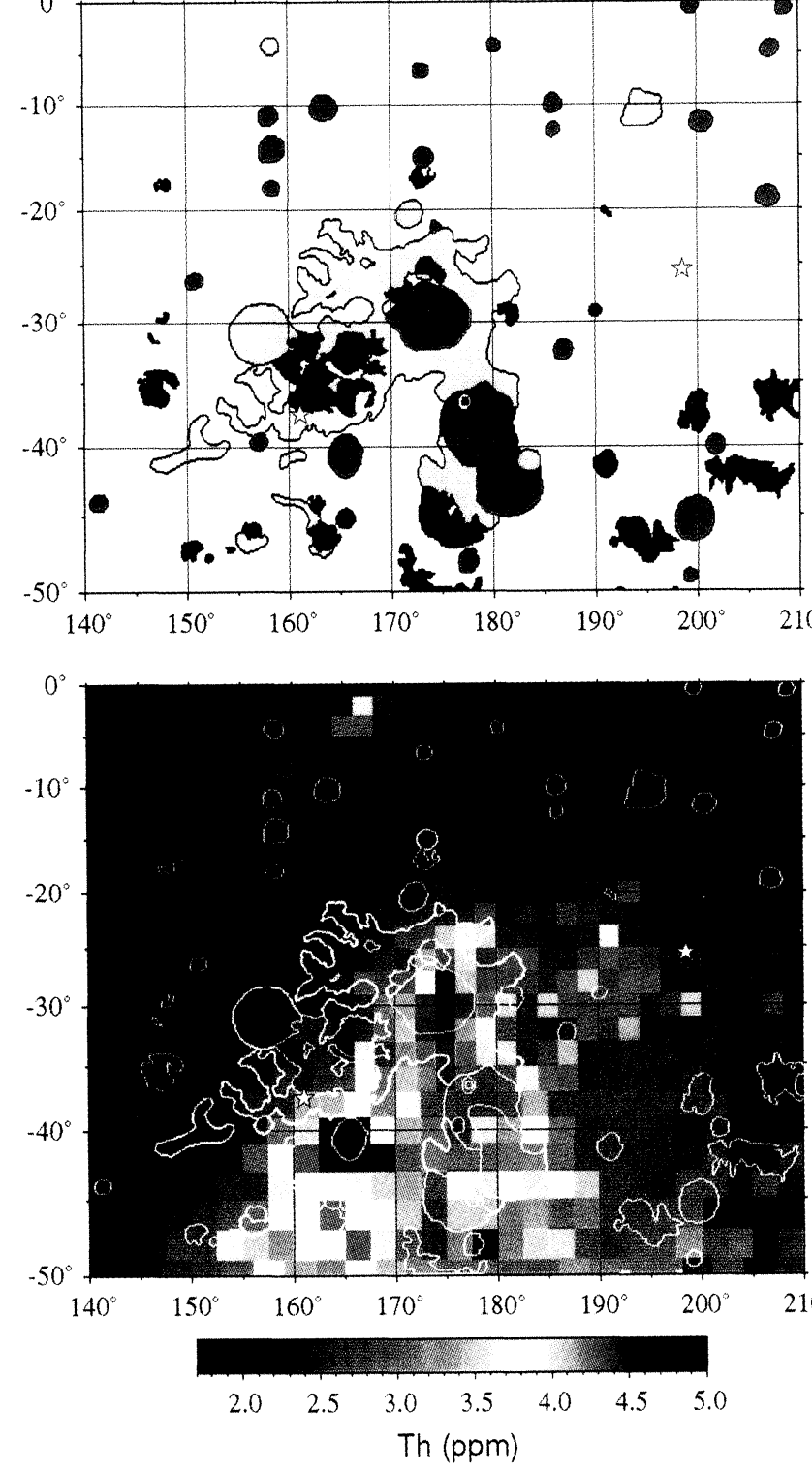

Plate 2. The top image is a simplified geologic map of the northern portion of the SPA basin based on the mapping of Stuart-Alexander [1978]. Yellow map units represent Copernican crater units, green represents Eratosthenian crater units, red represents Imbrian mare basalt deposits, and blue-gray represents the Imbrian grooves. Other map units of Stuart-Alexander [1978] show no correlation with the distribution of thorium in this region. The bottom plot shows the outlines of the above geologic units superposed on the $2^{\circ} \times 2^{\circ}$ thorium data of Lawrence et al. [1999]. Both images are presented in a Mercator projection, and the antipodes of the Imbrium and Serenitatis basins are shown for comparison. For reference, the large mare deposit that postdates the Imbrian grooves at $35^{\circ} \mathrm{S}$ and $165^{\circ} \mathrm{E}$ is Mare Ingenii. 
Table 1. Ejecta Modeling Parameters

\begin{tabular}{ccc}
\hline Parameter & Value & Source \\
\hline$K_{1}$ & 0.44 & average of values of Cintala et al. [1999] \\
$K_{3}$ & 0.08 & this study; see text \\
$e_{x}$ & 1.81 & water impact; Housen et al. [1983] \\
$e_{v}$ & 1.66 & water impact; Housen et al. [1983] \\
Radius of Imbrium's excavation cavity & $372 \mathrm{~km}$ & Wieczorek and Phillips [1999] \\
Imbrium basin center & $37.5^{\circ} \mathrm{N}, 19^{\circ} \mathrm{W}$ & this study \\
Radius of Serenitatis's excavation cavity & $329 \mathrm{~km}$ & Wieczorek and Phillips [1999] \\
Serenitatis basin center & $25.5^{\circ} \mathrm{N}, 18.5^{\circ} \mathrm{E}$ & this study \\
\hline
\end{tabular}

angle we compute the orbital elements of the ejecta's ballistic trajectory and determine at which point on the surface of the rotating planet that it eventually reimpacts (for comparison, see Moore et al. [1974], Ahrens and O'Keefe [1978], Dobrovolskis [1981], Alverez [1996], and Haskin [1998]).

In calculating the volume and velocity of material ejected from an impact crater, we use the ejecta scaling relationships of Housen et al. [1983]. Particularly,

$$
V_{e}(>v)=K_{3} R^{3}\left(\frac{v}{\sqrt{g R}}\right)^{-e_{v}}
$$

and

$$
v=K_{1} \sqrt{g R}\left(\frac{x}{R}\right)^{-e_{x}},
$$

where $V_{e}$ is the volume of material ejected having a velocity greater than $v, R$ is the radius of the crater's transient cavity, $g$ is the gravitational acceleration of the planet, $x$ is the distance from the center of the crater, and $K_{1}, K_{3}, e_{x}$, and $e_{v}$ are empirically determined scaling constants. Substituting the second equation into the first yields a relationship expressing the volume of material ejected at a radius less than $x$,

$$
V_{e}(<x)=V_{\mathrm{T}}\left(\frac{x}{R}\right)^{e_{\mathrm{r}} e_{x}}
$$

where the total volume of excavated material, $V_{\mathrm{T}}$, is given by

$$
V_{\mathrm{T}}=K_{1}{ }^{-e_{r}} K_{3} R^{3} \text {. }
$$

For $K_{1}$, we use the average of the values reported by Cintala et $a l$. [1999], while for $e_{x}$ and $e_{v}$ we use the "water impact" values reported by Housen et al. [1983] (see Table 1). We note that the above scaling relationships are strictly applicable only to nearvertical impacts.

The value of $K_{3}$ is probably the least certain of all the above scaling variables. Data from Andrews [1975] imply a value of 0.32 , whereas data from Stöfler et al. [1975] imply a value of $\sim 0.2$ [see Housen et al., 1983]. More recent experiments measuring higher velocity ejecta by Yamamota and Nakamura [1997] suggest that $K_{3}$ may be about an order of magnitude lower than the above estimates. We use a mass balance approach to better constrain the value of this constant. The geophysical structure of impact basins on the Moon suggests that the excavation cavity of these craters had a depth/diameter ratio of $\sim 0.1$ [Wieczorek and Phillips, 1999]. This value is consistent with theoretical models and experimental studies for impact craters orders of magnitude smaller in size and gives some credence to our using the laboratory-derived scaling relations for lunar impact basins. If the shape of the excavation cavity is parabolic with a depth/diameter ratio of 0.1 , then the expression for $V_{\mathrm{T}}$ implies that

$$
K_{3}=\frac{\pi}{10} K_{1}^{e^{e_{n}}} \text {. }
$$

For the values of $K_{1}$ and $e_{v}$ quoted in Table $1, K_{3}$ is here computed to be equal to 0.08 , which is about half of the value reported by Stöffler et al. [1975]. As the volume of material ejected at a given position in a crater is proportional to $K_{3}$, uncertainties in this parameter will only raise or lower the global thickness of a crater's primary ejecta deposit by a multiplicative constant.

The final piece of information that is needed to model a crater's distribution of ejecta is the angle that the ejected material's velocity vector makes with the surface. This has been investigated by Cintala et al. [1999], and in Figure 1 we plot all the ejection angle data from this study as a function of normalized crater radius. As is seen, there is considerable spread in the data. Nonetheless, the data appear to follow a power law in which the ejection angle decreases with increasing distance from the center of the crater.

At this point we can compute the velocity, angle, and volume of material that is ejected at each surface position within a crater of a given size. In our model we approximate the surface of the crater as discreet annuli increasing in radius by $0.1 \mathrm{~km}$, with each annulus being divided into $\sim 0.1-\mathrm{km}$-long segments. For each package of material that is ejected from this grid, we add the Moon's rotational velocity to the velocity obtained from the ejecta scaling relationships and then compute the orbital elements for this ballistic trajectory. The position at which this trajectory reimpacts the surface is finally determined on an $\sim 2^{\circ} \times 2^{\circ}$ equalarea grid using the spherical range equation, the time of flight of the material, and the Moon's angular rate of rotation [e.g. Dobrovolskis, 1981]. If the semimajor axis of the trajectory was found to exceed the Moon's sphere of influence [e.g., Roy, 1988], this material was excluded from consideration. Furthermore,

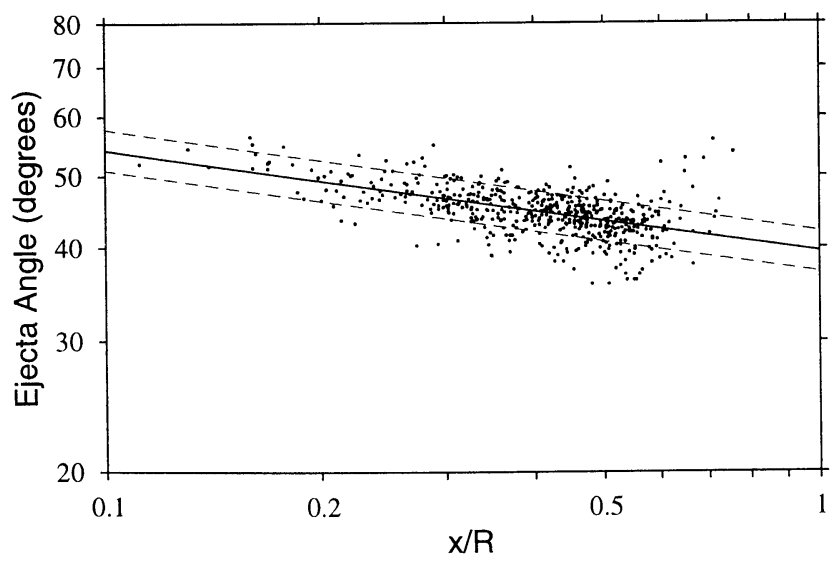

Figure 1. Plot showing the ejection angle of crater ejecta as a function of normalized crater radius from the data of Cintala et al. [1999]. The solid line is the least squares fit of $\alpha=a(x / R)^{-b}$, where $a=39.5, b=0.137$, and $\alpha$ is the ejection angle in degrees from the surface. Dashed lines represent the standard deviation of the data with respect to the best fit. 

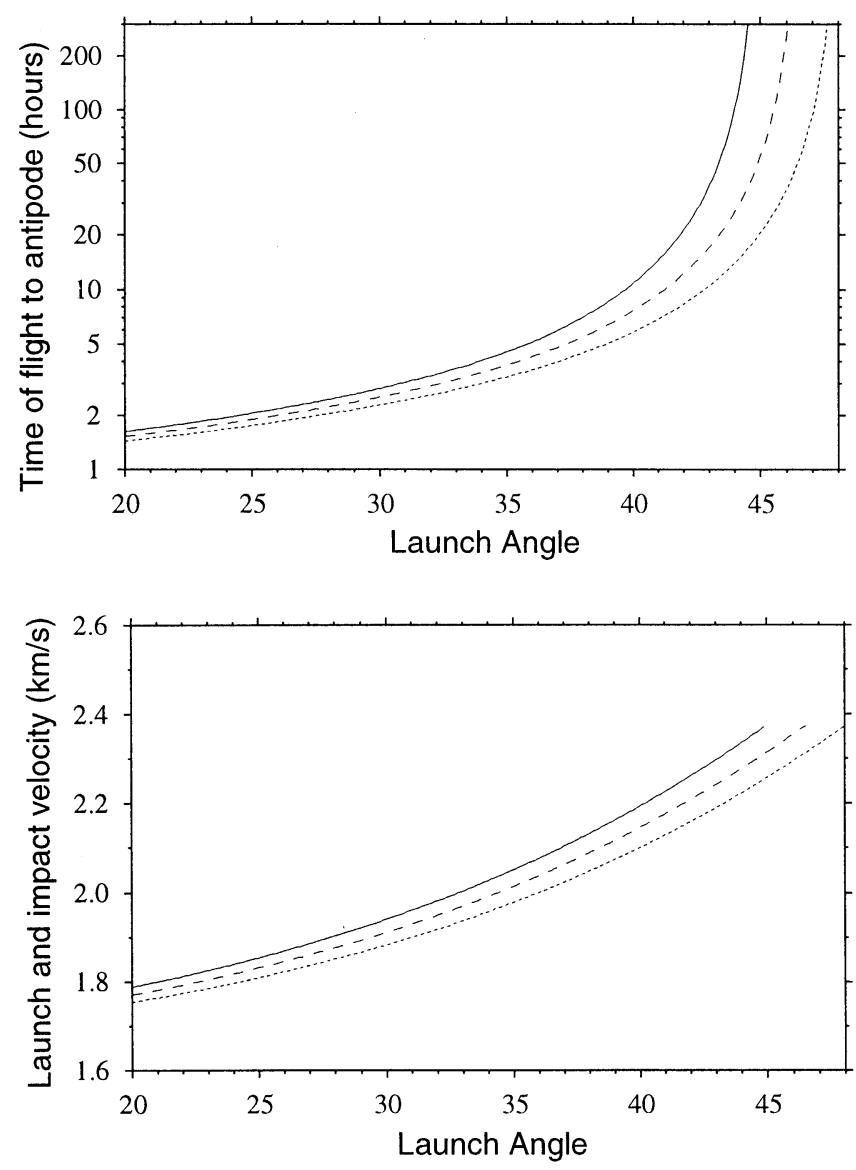

Figure 2. The top plot shows the time it takes for ejecta on a ballistic trajectory to reach the antipode of a crater as a function of launch angle. The bottom plot shows the launch and impact velocity of this ejecta as a function of ejection angle. For both plots the solid curve represents material ejected from the center of a crater, the dashed curve represents material ejected at half the radius of the Imbrium crater, and the dotted curve represents material ejected from the rim of the Imbrium crater.

material launched at velocities exceeding the Moon's escape velocity $(\sim 2.4 \mathrm{~km} / \mathrm{s})$ is put on hyperbolic orbits that do not reimpact the Moon. We note that the impact of the Imbrium bolide with the Moon would have had a negligible effect on the Moon's angular rate of rotation [e.g., Melosh, 1975]. Furthermore, we find it unlikely that the Imbrium impact would have substantially altered the Moon's orientation. This differs from the conclusion of Melosh [1975] in part because the geophysically inferred size of the Imbrium basin [Wieczorek and Phillips, 1999] is considerably smaller than the value adopted in the Melosh [1975] study. The basin floor also probably rebounded much faster (nearly instantaneously [e.g., Wieczorek and Phillips, 1999]) than was assumed by Melosh [1975] as well.

It is useful to illustrate the timescales involved with ballistic trajectories on the Moon. In Figure 2 we plot the time it takes for material to travel from a source crater to its antipode as a function of launch angle. (We note that the time of flight calculations presented by Schultz and Gault [1975] are inconsistent with our results and that one of the equations used by Ahrens and O'Keefe [1978] is off by a factor of 2. Our calculations are consistent with those of Dobrovolskis [1981]). Our results show that this time ranges from just a few hours when the ejection angle is small $\left(<35^{\circ}\right)$ to infinity as the launch angle approaches $45^{\circ}$. We also note that for the Imbrium impact in particular, material ejected at angles greater than $\sim 48^{\circ}$ can never make it to the antipode because at high velocities this material will escape the Moon's gravity on hyperbolic orbits. The bottom portion of Figure 2 shows that the launch and corresponding impact velocity necessary for material to reach the antipode is on the order of 2 $\mathrm{km} / \mathrm{s}$. Thus the ejecta that makes it to a basin's antipode on the Moon should reimpact under both hypervelocity and moderately oblique conditions.

\section{Results}

In this section we describe our ejecta modeling results for both the Imbrium and Serenitatis basins. We first describe the Imbrium results in which the impacting bolide is assumed to be close to vertical. Second, we describe how we approximate the effects of an oblique impact in our ejecta model and report our results for a putative oblique Imbrium impact. Finally, we describe our results for an oblique Serenitatis impact.

\subsection{Imbrium: Vertical Impact}

Before discussing our results for the Imbrium basin, we first show schematically how the Moon's rotation should affect the deposition of ejecta near a basin's antipode. In Figure 3, each circle represents material that was ejected from a basin at a given time and that was deposited near the basin's antipode. The smaller circles correspond to material ejected early in the growth of the crater's excavation cavity, and because of the high velocities associated with this material, this ejecta travels a long distance and has a correspondingly long time of flight. As a result of the Moon's eastward rotation, this ejecta eventually reimpacts the surface far to the west of the crater's antipode. The larger

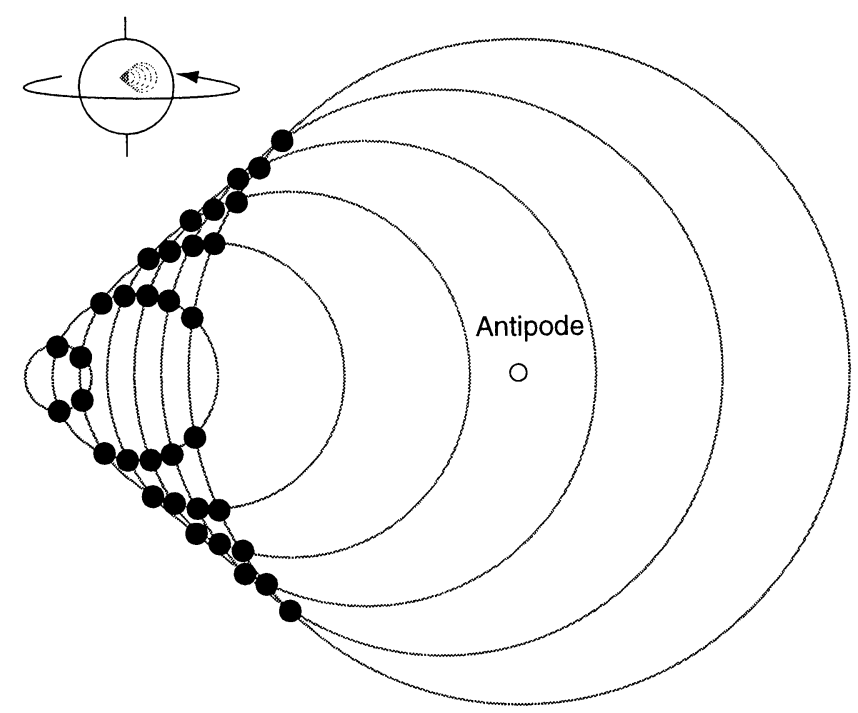

Figure 3. Schematic illustration showing how the Moon's rotation should affect the deposition of ejecta near a crater's antipode. Each circle represents material ejected from the crater at the same time. Smaller circles correspond to material ejected earlier and at higher velocities, whereas the larger circles correspond to material ejected later and at lower velocities. The thickness of the ejecta deposit will be largest where the circles intersect (solid dots). The inset illustrates the prograde rotation of the Moon. 

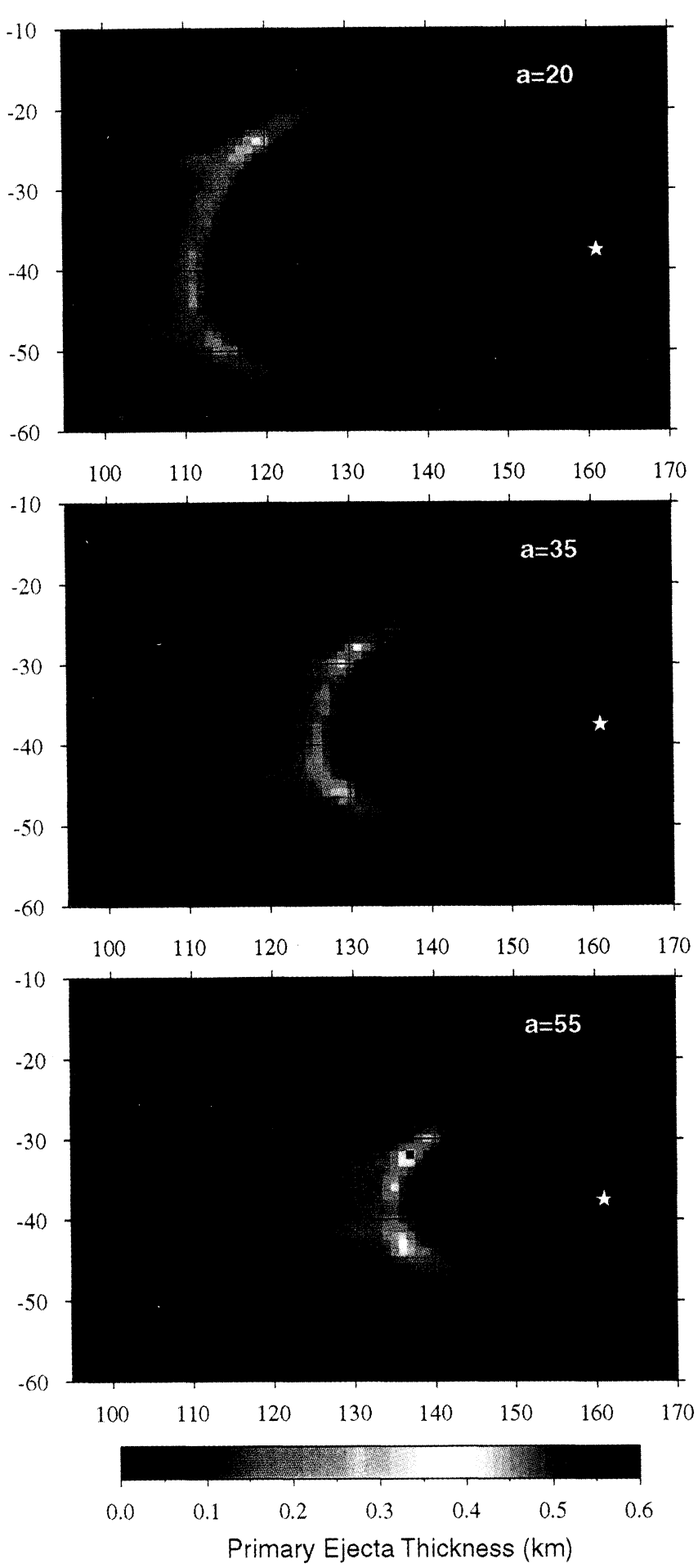

Plate 3. Modeled thickness of primary ejecta antipodal to the Imbrium impact for three different lunar rotation rates corresponding to when the Moon was at 20, 35, and 55 Earth radii (assuming synchronous rotation). White stars correspond to the antipode of the Imbrium basin, and the images are presented in a cylindrical projection.

circles represent material ejected later in the growth of the crater's excavation cavity. This material has correspondingly lower velocities and thus does not travel as far as the initial highvelocity material. Because of the shorter times of flight associated with this material, it reimpacts the surface only slightly to the west of the basin's antipode. Where these circles intersect (i.e., where the ballistic trajectories converge on the planet's surface), the amount of material deposited at these locations will be correspondingly greater. As Figure 3 illustrates, the distribution of antipodal ejecta should be offset to the west of the basin's antipode and should possess a crescent-like shape.

In our ejecta calculations for the Imbrium basin we found that the first $4 \%$ of ejected material escaped the Moon's gravity and that an additional $<0.1 \%$ of ejected material had semimajor axes that exceeded the Moon's sphere of influence. Plate 3 shows our model thickness of primary ejecta antipodal to the Imbrium basin for three different lunar rotation rates corresponding to when the Moon was at 20, 35, and 55 Earth radii. (Tides raised on the Moon quickly despin it to a state of synchronous rotation within $\sim 1$ Myr [e.g., Peale, 1977] The Moon thus remains synchronously locked as the lunar orbit tidally evolves outward.) Our model predicts that if this basin formed when the Moon was rotating close to its present rate, its ejecta should have been offset to the west of its antipode by $\sim 20^{\circ}$. More likely, if the Imbrium basin formed when the Moon was close to 35 Earth radii, then this offset should have been $\sim 30^{\circ}$. Thus, if Imbrium's antipoda ejecta distribution can be described using vertical impact-scaling relationships, then ejecta from this basin cannot be the cause of either the Imbrian grooves or high-thorium anomaly found within the South Pole-Aitken basin.

Plate 3 also demonstrates that Imbrium's primary ejecta should be only about half of a kilometer thick near its antipode. To assess the implications of this prediction, assume for the moment that Imbrium's primary ejecta had a thorium concentration of $10 \mathrm{ppm}$. When this material reimpacted the surface, it should have mixed and become diluted with a substantial amount of local highland materials (which contain

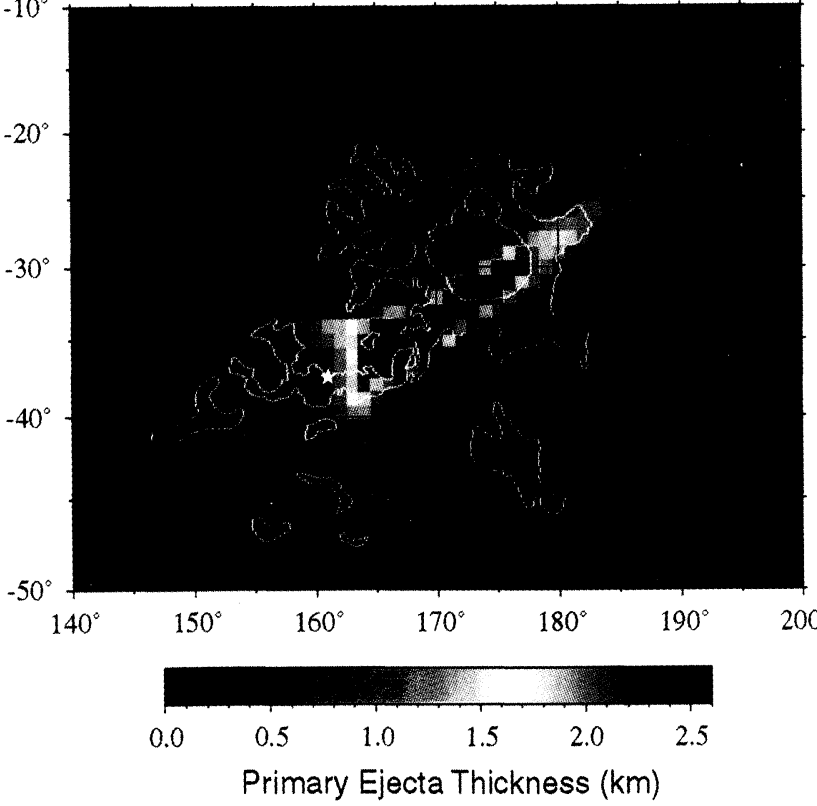

Plate 4. Outline of the distribution of Imbrian grooves superposed on the thickness of Imbrium's modeled antipodal ejecta. In this case the Imbrium bolide came from the southeast ( $115^{\circ}$ east of north), and a constant velocity tangential to the surface of $1 \mathrm{~km} / \mathrm{s}$ was added in this direction to the velocities determined from the vertical impact-scaling relationships. The white star represents the antipode of the Imbrium basin, and the image is presented in a Mercator projection. 


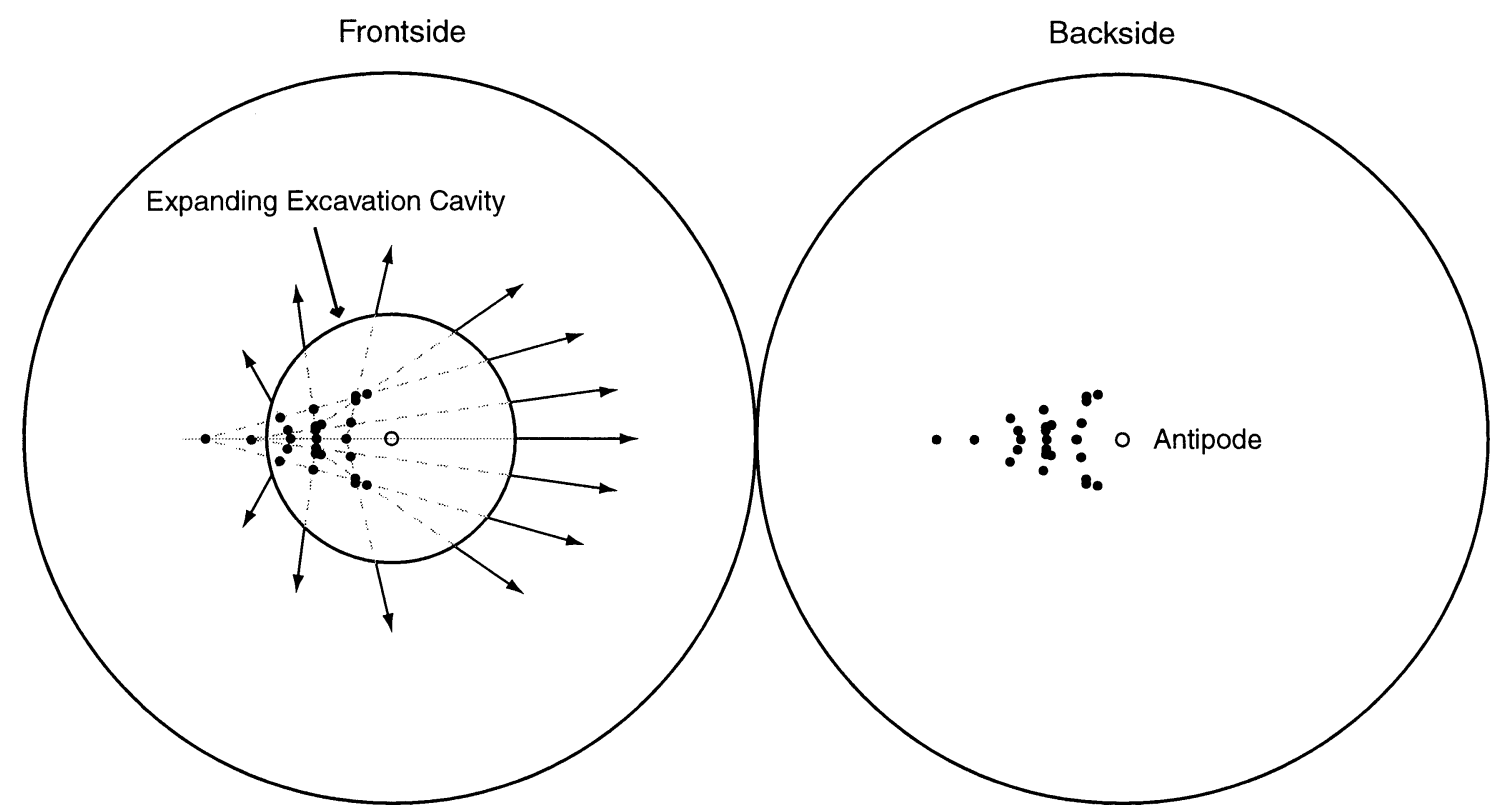

Figure 4. Schematic illustration of how an oblique impact introduces asymmetries in the velocity of ejected material, and its influence on the distribution of ejecta antipodal to the crater. The left half of the figure represents the frontside of the Moon, whereas the right half represents the Moon's farside. The direction of the impacting bolide is from west to east. The velocity vectors of the ejecta have been projected onto the surface of the planetary body, and the solid dots correspond to where the orbit planes of the ejecta intersect. Where the orbit planes intersect on the farside of the Moon, the thickness of the ejecta deposit will be increased.

only $\sim 1$-ppm thorium). While the proportion of primary ejecta in the final ejecta deposit is hard to quantify, it probably does not exceed 50\% near a basin's antipode [e.g., Haskin, 1998] Thus Imbrium's final antipodal ejecta deposit probably possessed no more than 5-ppm thorium and was probably no more than $1 \mathrm{~km}$ thick. Over four billion years, however, vertical impact gardening and the lateral transport of surface materials by continued impact cratering in the surrounding highlands should have further diluted the surface concentration of thorium in this deposit. As the width of our modeled antipodal ejecta deposit for the Imbrium basin is only $\sim 30 \mathrm{~km}$ wide, and the spatial resolution of the Lunar Prospector gamma-ray spectrometer is $\sim 60 \mathrm{~km}$, it seems questionable to us as to whether we would even be able to detect this putative deposit in the gamma-ray data.

We have run a number of simulations testing the sensitivity of our results to the assumed values of the impact-scaling constants and find that the uncertainty associated with the ejecta launch angle creates by far the largest variability in our model results. Though the uncertainty in this parameter does not substantially alter the above conclusions, as an extreme illustration of its effect, we have computed the thickness of Imbrium's antipodal ejecta using the \pm 1 standard deviation limits of the ejection angle data presented in Figure 1. Using the upper bound of this data, we find that Imbrium's ejecta should converge significantly farther to the west of its antipode (by more than $40^{\circ}$ ). Furthermore, the maximum thickness of this modeled ejecta deposit is only $\sim 0.25$ $\mathrm{km}$. Using the lower bound of the ejection angle data, we find that Imbrium's ejecta should converge more than $12^{\circ}$ to the west of its antipode and that the maximum thickness of this deposit should be $\sim 3 \mathrm{~km}$. Thus, if vertical impact-scaling relationships can be used to describe the Imbrium impact, its antipodal ejecta should almost certainly have converged outside the confines of the South Pole-Aitken basin.

\subsection{Imbrium: Oblique Impact}

While some aspects of oblique impacts have been investigated in laboratory experiments and computational simulations [e.g., Gault and Wedekind, 1978; Schultz and Gault, 1990; Schultz and Anderson, 1996; Pierazzo and Melosh, 1999, 2000a, 2000b], the effects of an oblique impact on the distribution of a crater's ejecta have not yet been quantitatively assessed. Nonetheless, from these studies, and from examples of oblique impacts on the terrestrial planets, some aspects of this process can be generalized. First, the initial downrange ejecta has a velocity that is higher and an ejection angle that is lower than that of a corresponding vertical impact. Conversely, the initial uprange material is ejected at an angle higher than that of a vertical impact [e.g., Gault and Wedekind, 1978; Schultz and Anderson, 1996]. Second, while the target's initial excavation flow field associated with an oblique impact is highly asymmetric, the final excavation flow field is approximately axisymmetric. This is clear from the observation that the rays of the lunar crater Tycho (which represent initial high-velocity ejecta) are asymmetrically distributed, whereas its continuous ejecta blanket is axisymmetric and its crater rim is circular [e.g., Schultz and Anderson, 1996].

These considerations suggest that the initial material ejected in an oblique impact may be qualitatively modeled by adding a constant velocity tangential to the surface in the impactor's direction to the ejecta velocities determined from the vertical impact-scaling relationships. This would have the effect of both increasing the initial downrange velocity of the ejected material and decreasing its angle of ejection. Figure 4 shows a schematic illustration of how an oblique impact may influence the distribution of ejecta at its antipode. For a specific instant in time, Figure 4 shows the velocity vectors of material being ejected from the crater's excavation cavity projected onto the surface of a sphere. As is seen, adding a constant velocity tangential to the 
surface to the axisymmetric vertical-impact ejecta velocities has the effect of rotating the ejecta velocity vectors in the downrange direction. The thickness of primary ejecta deposited on the farside on the Moon will be increased wherever the orbit planes of these ballistic trajectories intersect. This is illustrated by the solid dots in Figure 4 and shows that the antipodal ejecta should have a somewhat wedge-shaped pattern originating at the basin's antipode and pointing in the direction of the bolide's initial velocity vector.

Because of the simple way in which we approximate an oblique impact, we find in our models below that the ejection angles of the downrange ejecta have been reduced to such a point that the times of flight of the antipodal ballistic trajectories are insignificant compared to the rotational period of the Moon (see Figure 2). Explicitly including the Moon's rotation in these simplistic calculations would thus have little effect on the distribution of ejecta antipodal to the Imbrium basin. We regard this behavior as an artifact of our simplistic parameterization of the impact process and not a real effect. In addition to ignoring the Moon's rotation, we have also arbitrarily chosen the direction of the impacting bolide and the magnitude of the tangential velocity added to the vertical impact-scaling relationships such that the distribution of ejecta most closely fit the planform of the Imbrian grooves. Our results for this best case scenario are presented in Plate 4 . In this case the Imbrium bolide was traveling from the southeast $\left(115^{\circ}\right.$ east of north) when it struck the surface, and the magnitude of the tangential velocity vector added to the ejecta was $1 \mathrm{~km} / \mathrm{s}$.

As is seen in this image, the ejecta from this putative oblique Imbrium impact is distributed over the general vicinity of the Imbrian grooves. While an oblique impact can account for the northeast-southwest elongation of this feature, we find the correlation between this modeled ejecta deposit and the Imbrian grooves to be unsatisfactory in three ways. First, while our modeled ejecta deposit in this region is somewhat similar in form to our schematic in Figure 4 (the ejecta deposit points away from and is widest near its antipode), it appears to be pointing in the wrong direction. Namely, our modeled ejecta is pointing to the northeast (i.e., it is widest in the south), whereas the Imbrian grooves appear to be pointing to the southwest (i.e., it is widest in the north). Second, the modeled ejecta does not overlap the most southwestern portion of the Imbrian grooves unit. And third, there is no corroborating evidence that the Imbrium impact was indeed oblique from the southeast.

On the basis of the geomorphology of the Imbrium basin, it has been suggested that the Imbrium bolide came from the northnortheast [Baldwin, 1963], $70^{\circ}$ east or $110^{\circ}$ west of north [Wilhelms, 1987], or from the northwest [Wilhelms, 1987; Schultz, 1995]. None of these directions correspond to that required by our model. Furthermore, the geophysical signature of the Imbrium basin does not seem consistent with a projectile coming from the southeast. Plate 5 shows the geophysically inferred crustal thickness of the Imbrium basin, and there are no obvious signs for a symmetry axis in the northwest-southeast direction. In fact, it could be argued that this basin possesses a symmetry axis in the east-west direction based on the apparent lack of a thick ejecta blanket on the eastern rim of this basin. The above considerations thus suggest to us that the Imbrian grooves cannot be easily explained by the convergence of ejecta antipodal to the Imbrium basin, even if this impact was oblique.

\subsection{Serenitatis: Oblique Impact}

We have previously noted that both the Imbrian grooves and SPA thorium anomaly are located west of Serenitatis's antipode. In addition, these features are both found to occur at a latitude close to the antipode of this basin (see Plates 1 and 2). As a result of the Moon's prograde rotation, the Imbrian grooves and SPA thorium anomaly could thus possibly have had an origin related to the convergence of ejecta antipodal to the Serenitatis impact. Radiometric ages of samples that are believed to be derived from the Serenitatis basin suggest that this basin is probably no more than 50 million years older than the Imbrium impact [Dalrymple and Ryder, 1996]. Thus, while the Serenitatis basin is not technically of Imbrian age, we doubt if geologic mapping of the Moon's farside could distinguish between whether the "material of grooves and mounds" was the age of the Imbrium or Serenitatis impact. Since we cannot reconcile the Imbrian grooves with having an Imbrium origin, we next test the hypothesis that this feature is the result of ejecta converging near the antipode of the Serenitatis basin.

In Plate 5 we show the geophysically inferred crustal thickness of both the Serenitatis and Imbrium basins. This image emphasizes that these two impact craters are very similar in size, even though the mare fill associated with the Imbrium basin is comparatively greater in extent. Contrary to the Imbrium basin, the crustal structure of the Serenitatis basin possesses a strong bilateral symmetry axis, roughly in the north-south direction. In fact, with the possible exception of the Nectaris basin, Serenitatis has the most asymmetric crustal structure out of all the nearside basins with good gravity coverage. The asymmetric morphology of the Serenitatis basin was previously recognized in the geologic mapping of Scott [1972] and has been interpreted as being the result of two distinct impact events [e.g., Spudis, 1993].

On the basis of the inferred crustal structure of this basin and the morphology of oblique impact craters, we reinterpret the structure of the Serenitatis basin as being the result of a single oblique impact. While the oblique impact craters formed in the study of Gault and Wedekind [1978] suggest that the Serenitatis bolide may have came from the south, the experiments of Schultz and Gault [1990] and Schultz and Anderson [1996] allow for the possibility that this bolide may have come from the north. A Serenitatis bolide coming from the north is also consistent with the morphology of some highly oblique $\left(10^{\circ}\right.$ to $20^{\circ}$ from horizontal) Venusian impact craters [Schultz, 1992].

Recognizing that there may be some ambiguity in the direction of the Serenitatis bolide (north versus south), in our ejecta model we have chosen this bolide to have come from $12^{\circ}$ west of north, in accord with the geophysical structure of this basin. In order for our modeled distribution of antipodal ejecta to best match the planform of the Imbrian grooves, a velocity of $1.1 \mathrm{~km} / \mathrm{s}$ tangential to the surface was arbitrarily added in this direction to the ejecta velocities determined from the vertical impact-scaling relationships. Our modeled distribution of ejecta antipodal to the Serenitatis impact basin is shown in Plate 6, and the planform of this ejecta is seen to be similar to our schematic presented in Figure 4. This image demonstrates that for the case of an impact from the north, the ejecta antipodal to this basin points in a direction similar to that of the Imbrian grooves (i.e., the ejecta points away from its antipode towards the southwest and is widest near its antipode). The modeled ejecta from this basin is found to be offset roughly $18^{\circ}$ to the east of the Imbrian grooves, 


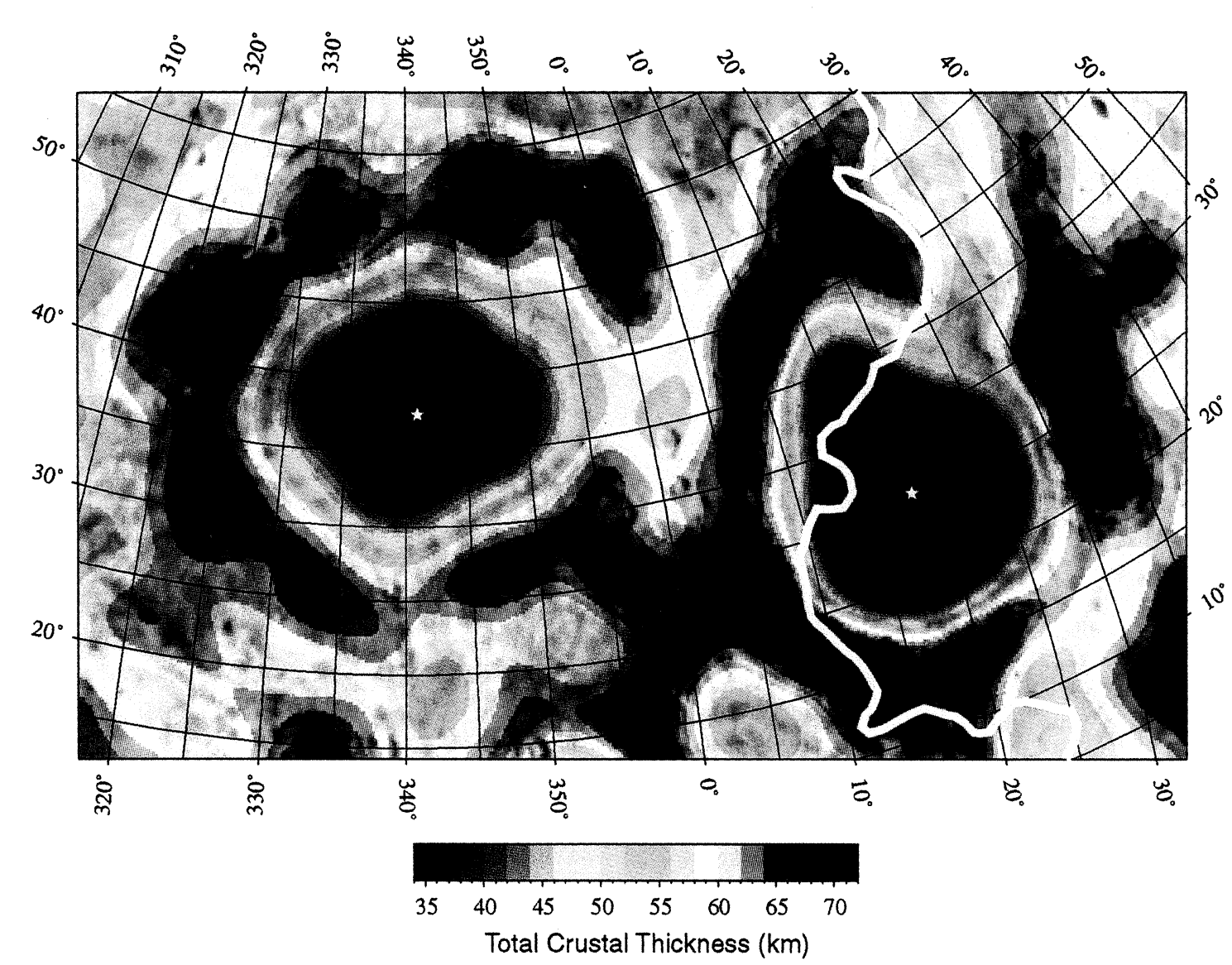

Plate 5. Total crustal thickness of the (left) Imbrium and (right) Serenitatis basins taken from the dual-layered crustal thickness model of Wieczorek and Phillips [1998], updated using the 100-degree Lunar Prospector gravity data of Konopliv et al. [1998]. The white line running through the Serenitatis basin represents the easternmost extent of the high-thorium Procellarum KREEP terrane (defined here by a contour of 3.5-ppm thorium). This image is presented in an Albers equal-area projection.

but because we did not include the Moon's rotation in our oblique model (see section 4.2) some amount of eastward displacement was to be expected. If the oblique impact process could be properly modeled, and the Moon's rotation could hence be taken into consideration, then this pattern of ejecta would

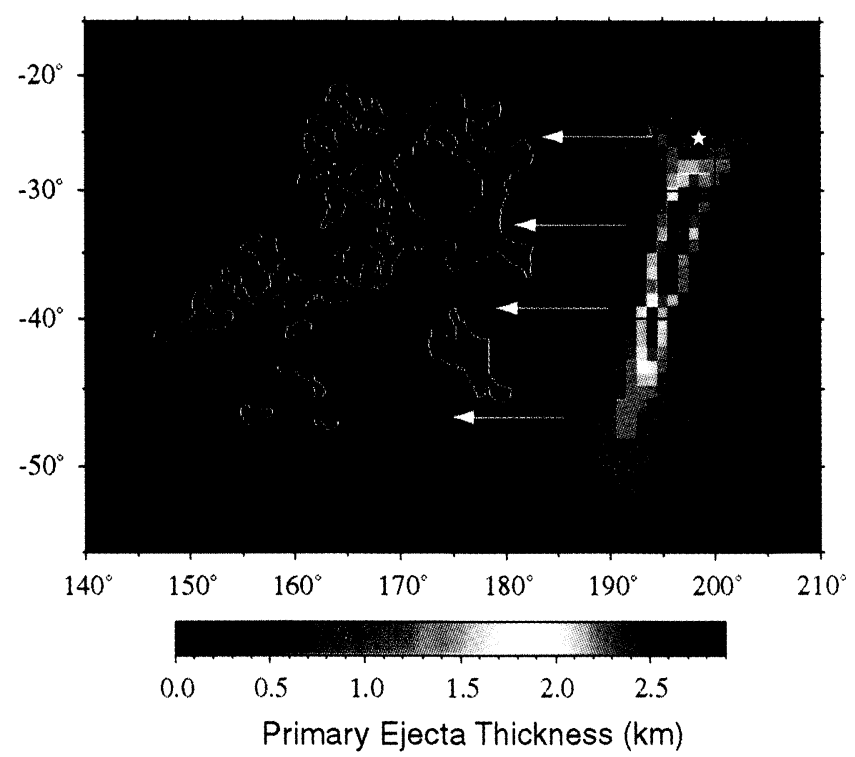

likely have more closely matched the distribution of the Imbrian grooves. It is thus a strong possibility that the Imbrian grooves and SPA thorium anomaly have an origin related to the convergence of ejecta antipodal to the Serenitatis basin.

While the distribution of ejecta antipodal to the Serenitatis basin bears a striking resemblance to the Imbrian grooves, there are three possible caveats associated with advocating a Serenitatis origin for this geologic feature. First, our model of the oblique impact process is only qualitative and does not take into account the rotation of the Moon. Thus we have no way to gauge as to whether $18^{\circ}$ of lunar rotation should, or could, have occurred between the time of the Serenitatis impact and the deposition of its antipodal ejecta. Given that it can take a considerable amount

Plate 6. Outline of the distribution of Imbrian grooves superposed on the thickness of Serenitatis's modeled antipodal ejecta. In this model the Serenitatis bolide came from the north ( $12^{\circ}$ west of north), and a constant velocity tangential to the surface of $1.1 \mathrm{~km} / \mathrm{s}$ was added in this direction to the velocities determined from the vertical impact-scaling relationships. The white star represents the antipode of the Serenitatis basin, and the white arrows illustrate the direction in which this ejecta deposit should have been translated if the Moon's rotation and the oblique impact process were properly modeled. The image is presented in a Mercator projection. 
of time for a crater's ejecta to reach its antipode (see Figure 2 and Plate 3 ), the $18^{\circ}$ of offset between our modeled distribution of ejecta and the Imbrian grooves is probably not a fatal objection to our hypothesis that the Imbrian grooves have a Serenitatis origin. Second, in order for the planform of Serenitatis's antipodal ejecta to match that of the Imbrian grooves, we needed to choose the direction of the Serenitatis bolide to have come from the north. While this is consistent with the north-south bilateral symmetry of the Serenitatis basin and the morphology of highly oblique Venusian impact craters [Schultz, 1992], showing that this bolide actually came from the south would disprove our hypothesis. Finally, even though the orientation of Serenitatis's antipodal ejecta is similar to that of the Imbrian grooves, our modeled distribution of ejecta appears to be rotated counterclockwise by $\sim 30^{\circ}$. This discrepancy might be related to the complexities in how the ejection angle of material in an oblique impact changes with both time and position [e.g., Schultz and Anderson, 1996] This discrepancy could also partially be the result of uncertainties associated with our crustal thickness model of the Serenitatis basin, or possibly to our neglect of the Earth's gravity in computing the ballistic trajectories of basin ejecta.

\section{Discussion}

Our results for modeling the distribution of ejecta antipodal to the Imbrium basin imply that its ejecta is not likely the origin of either the Imbrian grooves or thorium anomaly that are found within the South Pole-Aitken basin. Instead, we have argued that these features could have formed by the convergence of ejecta antipodal to an oblique Serenitatis impact. Comparing the thickness of ejecta from our vertical and oblique models of the Imbrium impact (see Plates 3 and 4) further suggests that an oblique impact may in fact be necessary in order to concentrate a significant amount of ejecta near a basin's antipode. Thus grooved terrain antipodal to an impact basin might form only if the impact event was sufficiently oblique.

If the Imbrian grooves do in fact have a Serenitatis origin, then this conclusion has two implications that we discuss below. First, the Serenitatis target must have possessed a significant concentration of thorium, and second, the convergence of seismic waves antipodal to an impact basin should not be expected to cause significant modification of surface features.

\subsection{Composition of the Serenitatis Target}

Gamma-ray data obtained from the Lunar Prospector mission have demonstrated that the region encompassing Oceanus Procellarum and Mare Imbrium is a unique geologic crustal province enriched in incompatible and heat-producing elements (the "Procellarum KREEP terrane" of Jolliff et al. [2000] and Wieczorek and Phillips [2000]; see also Lawrence et al., [1998, 1999], Elphic et al. [1999], and Haskin [1998]). Since the Imbrium basin formed within this region of the Moon, it would be expected that the ejecta from this impact would be enriched in incompatible elements as well. Indeed, ejecta modeling by Haskin [1998] has shown that most of the thorium at the Moon's surface can be interpreted as being the result of the deposition of thorium-rich ejecta from this young impact event. This observation led Haskin et al. [1998] to argue that the thoriumrich mafic impact-melt breccias in the Apollo sample collection are the carriers of the remotely sensed thorium signature observed at the Moon's surface and furthermore that all of these impact melts have a common origin in the Imbrium impact.
If our hypothesis that the Imbrian grooves were formed by ejecta from the Serenitatis basin is correct, and if the SPA thorium anomaly and Imbrian grooves have a common origin (see section 2), then this implies that at least some of the ejecta from the Serenitatis basin had a high concentration of thorium as well. The concentration of thorium in the Imbrian grooves is probably $\sim 5 \mathrm{ppm}$ (see Plate 2), and because this deposit represents a mixture of both primary and secondary ejecta, Serenitatis's primary ejecta probably had a thorium concentration of $\sim 10 \mathrm{ppm}$ (see section 4.1). This value is similar to that observed for both the impact-melt breccias that are believed to be derived from the Imbrium impact [e.g., Korotev, 2000] and the concentration of thorium found in Imbrium's near-field ejecta blanket as determined from the Lunar Prospector gamma-ray data [e.g., Lawrence et al., 1998, 1999]. Furthermore, Plate 5 shows that the Serenitatis basin formed right on the boundary of the thorium-rich Procellarum KREEP terrane.

From the above considerations it thus seems probable that some of the ejecta from the Serenitatis basin was similar in composition to that of the neighboring Imbrium basin. The entire Serenitatis target, however, was probably not uniformly enriched in thorium. For instance, the terrain directly east of the Serenitatis basin (where we would expect to find Serenitatis's continuous ejecta blanket) does not show a noticeable thorium enrichment, implying that the eastern portion of the pre-Serenitatis substrate was probably composed of more "typical" highlands material. Since the high-velocity ejecta that makes it to the antipode of a basin comes from the central portion of its excavation cavity, in order for Serenitatis's antipodal ejecta to show a thorium enhancement, we require only that about half of its target was enriched in thorium.

While the above inference implies that some of the thoriumrich impact-melt breccias in the Apollo sample collection may have a Serenitatis origin, as Haskin et al. [1998, p. 971] noted, "this does not negate [an Imbrium] origin for most Th-rich mafic impact melt breccias or the possibility that most of the Th at the Moon's surface was placed there as Imbrium ejecta." In arguing for the case that all thorium-rich impact melts on the Moon had an Imbrium origin, however, they were forced to question the putative Serenitatis origin of the Apollo 17 poikilitic melt rocks and thus whether the age of the Serenitatis impact derived from their associated radiometric ages was valid. Since the results from this study suggest that some of the thorium-rich impact melts could have a Serenitatis origin, this gives some support to the validity of the 3.893-Gyr radiometric age of the Serenitatis basin as advocated by Dalrymple and Ryder [1996].

\subsection{Seismic Modification at the Antipodes of Impact Basins}

When the "material of grooves and mounds" on the Moon and the "hilly and lineated material" on Mercury were first discovered, Schultz [1972] and Schultz and Gault [1975] suggested that these features could have formed by the convergence of seismic waves antipodal to the Imbrium and Caloris basins, respectively. As the antipodes of these impact basins are expected to undergo kilometer-scale surface displacements with accelerations approaching that of the Moon's surface gravity [Hughes et al., 1977; Watts et al., 1991], some form of surface modification is to be expected. We acknowledge that the focusing of seismic energy may help to subdue the surface topography of features antipodal to a basin. The convergence of seismic energy also appears necessary as a shockmagnetization mechanism for retaining the strong magnetic 
anomalies that form antipodal to impact basins in the model of Hood and Huang [1991]. The results of our ejecta modeling, however, provide an alternative explanation for the origin of the Moon's material of grooves and mounds and Mercury's hilly and lineated material.

We have two objections to the hypothesis that these antipodal features could have formed solely by the convergence of seismic waves. First, even if our hypothesis that the Imbrian grooves were formed by Serenitatis ejecta is completely wrong, then why is it that the Serenitatis antipode lacks surface features similar to that of the Imbrian grooves? The Serenitatis basin is almost as large as the Imbrium basin (see Table 1 and Plate 5) and furthermore appears to have formed no more than $50 \mathrm{Myr}$ before the Imbrium basin [Dalrymple and Ryder, 1996]. The seismic energy that converged antipodal to the Serenitatis basin should have been similar in magnitude to that of the Imbrium basin and should thus have caused just as much surface damage, yet there is no morphologic evidence that this has occurred. Additionally, the similar ages of these two basins suggest that impact degradation of a putative "Serenitatis grooves" unit would have been no greater than for that which has occurred to the Imbrian grooves and thus should still be recognizable. Second, the planform of the Imbrian grooves is wedge shaped, consistent with our oblique ejecta modeling. We find it doubtful that the convergence of seismic energy would produce such a localized geometric distribution of deformation.

Our results for the Moon suggest that the material of grooves and mounds formed by the convergence of ejecta antipodal to the Serenitatis basin and that the convergence of seismic energy played little to no role in this feature's formation. If these results can be extrapolated to Mercury, then this suggests that the convergence of seismic energy antipodal to the Caloris basin need not be required to explain the origin of the hilly and lineated terrain found there. Though this geologic unit has not been fully mapped as a result of the limited photographic coverage of this planet, the planform of the hilly and lineated terrain appears to be elongated to the west of Caloris's antipode [see Trask and Dzurisin, 1984]. We hence suggest that the convergence of ejecta from an oblique Caloris impact from the west is the ultimate origin of this geomorphologic feature.

\section{Conclusions}

The Imbrian grooves and thorium anomaly within the South Pole-Aitken basin have long been believed to have an Imbrium origin. This hypothesis was based on the near-antipodal location of these surface features as well as the expectation that ejecta and seismic waves from this impact should have converged near its antipode. We have investigated the hypothesis that the Imbrium grooves and SPA thorium anomaly formed by the convergence of ejecta at this basin's antipode by modeling the deposition of ejecta on a rotating, spherical body. We have found that if the Imbrium bolide struck the surface at a near-vertical incidence angle, its distribution of ejecta would have been offset by more than $12^{\circ}$ to the west of its antipode. While including oblique impact effects in the deposition of this basin's ejecta can account for the northeast elongation of the Imbrium grooves, the planform of our modeled antipodal ejecta is found to be distinctly different from that of the Imbrian grooves. The convergence of ejecta antipodal to the Imbrium impact is thus not likely to have been the origin of the Imbrian grooves and its associated thorium anomaly.
As an alternative explanation, we have investigated the possibility that the Imbrian grooves formed as a result of the convergence of ejecta antipodal to an oblique Serenitatis impact. The Imbrian grooves and this basin's antipode are found to occur at similar latitudes and furthermore are offset in the direction expected as a result of the Moon's prograde rotation. If the Serenitatis bolide came from the north (consistent with the northsouth crustal thickness bilateral symmetry of this basin), then we find that the distribution of this basin's antipodal ejecta should have been similar to that of the planform of the Imbrian grooves. While our modeled distribution of Serenitatis ejecta is offset to the east of the Imbrian grooves, this is likely to be a consequence of our inability to model the Moon's rotation in our simplified parameterization of the oblique impact process. Though a more realistic model of how oblique impact conditions affect the ejection angle and velocity of crater ejecta is needed, at present the most likely origin of the Imbrian grooves and SPA thorium anomaly is that these features formed by the convergence of ejecta antipodal to the Serenitatis basin.

If this conclusion can be substantiated once quantitative oblique impact-scaling laws are determined, then this implies that like the Imbrium target, some portion of the Serenitatis target also possessed a high concentration of thorium. Furthermore, the convergence of seismic waves antipodal to an impact basin may not cause significant modification of surface features. Extrapolating this last result to the Caloris basin on Mercury suggests that the hilly and lineated terrain found at this basin's antipode can be explained by the convergence of this basin's ejecta, rather than its seismic energy.

Acknowledgments. We thank Larry Haskin for an insightful and constructive review of this paper. This research was supported by the Lunar Data Analysis Program under NASA grant NAG5-8707.

\section{References}

Ahrens, T.J., and J.D. O'Keefe, Energy and mass distributions of impact ejecta blankets on the Moon and Mercury, Proc. Lunar Planet. Sci. Conf. 9th, 3787-3802, 1978.

Alverez, W., Trajectories of ballistic ejecta from the Chixulub crater, Spec. Pap. Geol. Soc. Am., 307, 141-150, 1996.

Andrews, R.J., Origin and distribution of ejecta from near-surface laboratory-scale cratering experiments, $A F W L-T R-74-314,207$ pp., Air Force Weapons Lab., Kirtland Air Force Base, N.M., 1975.

Baldwin, R.B., The Measure of the Moon, 488 pp., Univ. of Chicago Press, Chicago, Ill., 1963.

Cintala, M.J., L. Berthoud, and F. Hörz, Ejection-velocity distributions from impacts into coarse-grained sand, Meteorit. Planet. Sci., 34, 605623, 1999.

Dalrymple, G.B., and G. Ryder, Argon-40/argon-39 age spectra of Apollo 17 highlands breccia samples by laser step heating and the age of the Serenitatis basin, J. Geophys. Res., 101, 26,069-26,084, 1996.

Dobrovolskis, A., Ejecta paterns diagnositic of planetary rotations, Icarus, 47, 203-219, 1981

Elphic, R.C., S. Maurice, D.J. Lawrence, W.C. Feldman, B.L. Barraclough, A.B. Binder, and P.G. Lucey, Lunar Prospector measurements of the distribution of incompatible elements gadolinium, samarium and thorium (abstract), Lunar Planet. Sci. [CDROM], $X X X$, abstract 1109,1999

Gault, D.E., and J.A. Wedekind, Experimental studies of oblique impact, Proc. Lunar Planet. Sci. Conf. 9th, 3843-3875, 1978.

Haskin, L.A., The Imbrium impact event and the thorium distribution at the lunar highlands surface, J. Geophys. Res., 103, 1679-1689, 1998.

Haskin, L.A., W.B. McKinnon, and L.A.M. Benner, Could Imbrium ejecta be the source of the high-Th material in the Van de Graaff region of the Moon? Lunar Planet. Sci., XXVII, 501-502, 1996.

Haskin, L.A., R.L. Korotev, K.M. Rockow, and B.L. Jolliff, The case for an Imbrium origin of the Apollo thorium-rich impact-melt breccias, Meteorit. Planet. Sci., 33, 959-975, 1998. 
Haskin, L.A., J.J. Gillis, R.L. Korotev, and B.L. Jolliff, The materials of the lunar Procellarum KREEP Terrane: A synthesis of data from geomorphological mapping, remote sensing, and sample analyses, $J$. Geophys. Res., 105, 20,403-20,415, 2000.

Hood, L.L., and Z. Huang, Formation of magnetic anomalies antipodal to lunar impact basins: Two-dimensional model calculations, J. Geophys. Res., 96, 9837-9846, 1991.

Hood, L.L., and C.R. Williams, The lunar swirls: Distribution and possible origins, Proc. Lunar Planet. Sci. Conf. 19th, 99-113, 1989.

Housen, K.R., R.S. Schmidt, and K.A. Holsapple, Crater ejecta scaling laws: Fundamental forms based on dimensional analysis, J. Geophys. Res., 88, 2485-2499, 1983.

Hughes, H.G., F.N. App, and T.R. McGetchin, Global seismic effects of basin-forming impacts, Phys. Earth Planet. Inter., 15, 251-263, 1977.

Jolliff, B.L., J.J. Gillis, L. Haskin, R.L. Korotev, and M.A. Wieczorek, Major lunar crustal terranes: Surface expressions and crust-mantle origins, J. Geophys. Res., 105, 4197-4216, 2000.

Konopliv, A.S., A.B. Binder, L.L. Hood, A.B. Kucinskas, W.L. Sjogren, and J.C. Williams, Improved gravity field of the Moon from Lunar Prospector, Science, 281, 1476-1480, 1998.

Korotev, R.L., The great lunar hot spot and the composition and origin of the Apollo mafic ("LKFM") impact-melt breccias, J. Geophys. Res., 105, 4317-4345, 2000.

Lawrence, D.J., W.C. Feldman, B.L. Barraclough, A.B. Binder, R.C. Elphic, S. Maurice, and D.R. Thomsen, Global elemental maps of the Moon: The Lunar Prospector gamma-ray spectrometer, Science, 281, 1484-1489, 1998.

Lawrence, D.J., W.C. Feldman, B.L. Barraclough, A.B. Binder, R.C. Elphic, S. Maurice, M.C. Miller, and T.H. Prettyman, High resolution measurements of absolute thorium abundances on the lunar surface, Geophys. Res. Lett., 26, 2681-2684, 1999.

Lawrence, D.J., W.C. Feldman, B.L. Barraclough, A.B. Binder, R.C. Elphic, S. Maurice, M.C. Miller, and T.H. Prettyman, Thorium abundances on the lunar surface, J. Geophys. Res., 105, 20,30720,331, 2000.

Melosh, H.J., Large impact craters and the Moon's orientation, Earth Planet. Sci. Lett., 26, 353-360, 1975.

Moore, H.J., C.A. Hodges, and D.H. Scott, Multiring basins-Illustrated by Orientale and associated features, Proc. Lunar Sci. Conf. 5th, 71100, 1974.

Peale, S.J., Rotation histories of the natural satellites, in Planetary Satellites, edited by J.A. Burns, pp. 87-112, Univ. of Ariz. Press, Tucson, 1977.

Pierazzo, E., and H.J. Melosh, Modeling of Chixulub as an oblique impact event, Earth Planet. Sci. Lett., 165, 163-176, 1999

Pierazzo, E., and H.J. Melosh, Melt production in oblique impacts, Icarus, 145, 252-261, 2000a.

Pierazzo, E., and H.J. Melosh, Understanding oblique impacts from experiments, observations, and modeling, Annu. Rev. Earth Planet Sci., 28, 147-167, 2000b.
Roy, A.E., Orbital Motion, 532 pp., Adam Hilger, Philadelphia, Pa., 1988.

Schultz, P.H., Moon Morphology, 626 pp., Univ. of Tex. Press, Austin, 1972.

Schultz, P.H., Atmospheric effects on ejecta emplacement and crater formation on Venus from Magellan, J. Geophys. Res., 97, 16,18316,248, 1992.

Schultz, P.H., Making the man in the Moon: Origin of the Imbrium basin (abstract), Lunar Planet. Sci., XXVI, 1251-1252, 1995.

Schultz, P.H., and R.R. Anderson, Asymmetry of the Manson impact structure: Evidence for impact angle and direction, Spec. Pap. Geol. Soc. Am., 302, 397-417, 1996.

Schultz, P.H., and D.E. Gault, Seismic effects from major basin formations on the Moon and Mercury, Moon, 12, 159-177, 1975.

Schultz, P.H., and D.E. Gault, Prolonged global catastrophes from oblique impacts, Spec. Pap. Geol. Soc. Am., 247, 239-261, 1990.

Scott, D.H., Geologic map of the Eudoxus quadrangle of the Moon, U.S. Geol. Surv. Map, I-705, 1972.

Spudis, P.D., The Geology of Multi-Ring Impact Basins, Cambridge Univ. Press, New York, 1993.

Stöffler, D., D.E. Gault, J. Wedekind, and G. Polkowski, Experimental hypervelocity impact into quartz sand: Distribution and shock metamorphism of ejecta, J. Geophys. Res., 80, 4062-4077, 1975.

Stuart-Alexander, D.E., Geologic map of the central far side of the Moon, U.S. Geol. Surv. Map, I-1047, 1978

Trask, N.J., and D. Dzurisin, Geologic map of the discovery quadrangle of Mercury, U.S. Geol. Surv. Map, I-1658, 1984.

Watts, A.W., R. Greeley, and H.J. Melosh, The formation of terrains antipodal to major impact basins, Icarus, 93, 159-168, 1991.

Wieczorek, M.A., and R.J. Phillips, Potential anomalies on a sphere: Applications to the thickness of the lunar crust, J. Geophys. Res., 103, $1715-1724,1998$

Wieczorek, M.A., and R.J. Phillips, Lunar multiring basins and the cratering process, Icarus, 139, 246-259, 1999.

Wieczorek, M.A., and R.J. Phillips, The Procellarum KREEP terrane Implications for mare volcanism and lunar evolution, J. Geophys. Res., 105, 20,417-20,430, 2000.

Wilhelms, D.E., The geologic history of the Moon, U.S. Geol. Surv. Spec. Pap., 1348, 1987.

Wilhelms, D.E., and F. El-Baz, Geologic map of the east side of the Moon, U.S. Geol. Surv. Map, I-948, 1997.

Yamamota, S., and A.M. Nakamura, Velocity measurements of impact ejecta from regolith targets, Icarus, 128, 160-170, 1997.

M. A. Wieczorek and M. T. Zuber, Department of Earth, Atmospheric and Planetary Sciences, Massachusetts Institute of Technology, 54-520, Cambridge, MA 02139. (markw@quake.mit.edu)

(Received September 13, 2000; revised January 30, 2001; accepted February 19, 2001.) 